\title{
Is Central Retinal Vein Occlusion (CRVO) due to hereditary ischemia risk factors?
}

\author{
Babak $\mathbf{A}^{1^{*}}$, Soheila $\mathbf{Z}^{2}$, Pouria $\mathbf{S}^{1}$ \\ ${ }^{1}$ Department of Pediatrics, Lorestan University of Medical Sciences, Khoramabad Lorestan, Iran \\ ${ }^{2}$ Department of Pediatrics, Shiraz University of Medical Sciences, Shiraz, Iran
}

\begin{abstract}
Introduction: Central retinal vein occlusion is one of the major causes of severe vision impairment and blindness in adults.

Case presentation: We present a case of unilateral ischemic central retinal vein occlusion in a 33-year-old man without any acquired ischemia risk factors and glaucoma. Laboratory tests including homocysteine and lipoprotein (a) were increased.

Conclusion: Our case illustrates an interesting presentation of unilateral ischemic central retinal vein occlusion, without main risk factors. Thrombophilia screening may be considered in selected cases.
\end{abstract}

Keywords: Central retinal vein occlusion, Thrombophilia.

\section{Introduction}

Thrombophilia can be defined as a predisposing factor for clot formation inappropriately, leading to significant mortality and morbidity. This situation can arise from genetic or acquired factors or, more commonly, an interaction between them [1].

Adulthood or late onset occurrence of thrombophilic events commonly have acquired risk factors such as age, smoking, hyperlipidemia, hypertension, diabetes mellitus, rise in intraocular pressure and oral contraceptive pills; rarely do hereditary thrombophilia, inherited deficiency of antithrombin or protein $\mathrm{C}, \mathrm{S}$ and factor $\mathrm{V}$ Lieden or metabolic disorders such as homocysteinemia or excess lipoproteine(a) result in this phenomenon [2].

Retinal vein occlusion (RVO) is a common cause of vision loss in older individuals, and the second most common retinal vascular disease after diabetic retinopathy [3]. RVO is not associated with direct measures of atherosclerosis, and other predisposing factors of vascular disease.

RVO mostly result from hereditary thrombophilic risk factors, especially hyperhomocysteinaemia among patients $\leq 45$ years of age or among patients with a remarkable family history of thromboembolism prior to the age of 45 years, or among patients without cardiovascular risk factors [4].

In populations a less, common type of RVO is central retinal vein occlusion (CRVO) [5]. Raised intraocular pressure is local risk factor for CRVO but, there is no strong association with hereditary thrombophilia and CRVO [6]. In this article we present a young man with CRVO associated with two hereditary risk factors and without acquired risk factors.

\section{Case Presentation}

A 33-year-old man presented to the ophthalmology department. He suffered from sudden onset and painless visual loss over the previous one week. His visual acuity on a standard Snellen chart was $6 / 60$ in his right eye and normal left eye vision.
He had no other symptoms other than visual loss, occasional headaches and recently increasing breathlessness on exertion. Previously he had had good vision, not requiring correction. $\mathrm{He}$ did not have any risk factors for ischemic heart disease such as smoking or obesity.

His conjunctivae were normal. Blood pressure was 112/60 $\mathrm{mmHg}$ and pulse rate were 92 beats per minute. Examination of the chest and abdomen was normal.

Fundal examination had all the features of right central retinal vein occlusion with both deep and superficial hemorrhages involving all four quadrants of the retina on each side, as well as marked optic disc edema and dilated, tortuous retinal veins. Intraocular pressures were normal (Figure 1).

Narrow-angle glaucoma, dehydration, retinal inflammatory diseases, and congenital tortuosity were not observed.

Blood film showed a normal pattern with any nucleated red cells, macrocytosis and hyper segmented neutrophils. Absolute reticulocyte count was not raised. Low levels of folate and vitamin B12 were confirmed on serum testing (folate: $10 \mathrm{ng} / \mathrm{ml}$, vitamin B12: $500 \mathrm{ng} / \mathrm{l}$ ). Also, he received Enoxaparin $1 \mathrm{mg} / \mathrm{kg}$ 2 times per day for 4 days and Warfarin $5 \mathrm{mg}$ was started daily 96 hours after beginning Enoxaparin (Table 1).

\section{Discussion}

The most common causes of the CRVO are acquired risk factors such as hypertension, diabetes, hyperlipidemia, glaucoma, smoking, and age-related atherosclerosis and there is no significant relationship between CRVO and hereditary predisposing factors [7]

Our patient had two hereditary risk factors but, he did not have any acquired risk factors of thrombophilia. Many (96\%) RVO patients have a minimum of one of the common acquired vascular risk factors. Simultaneous occurrence between CRVO and hereditary predisposing factors may be the result of laboratory 
Citation: Babak A, Soheila Z, Pouria S. Is Central Retinal Vein Occlusion (CRVO) due to hereditary ischemia risk factors? J Neurol Neurorehabil Res. 2018;3(1):9-11.

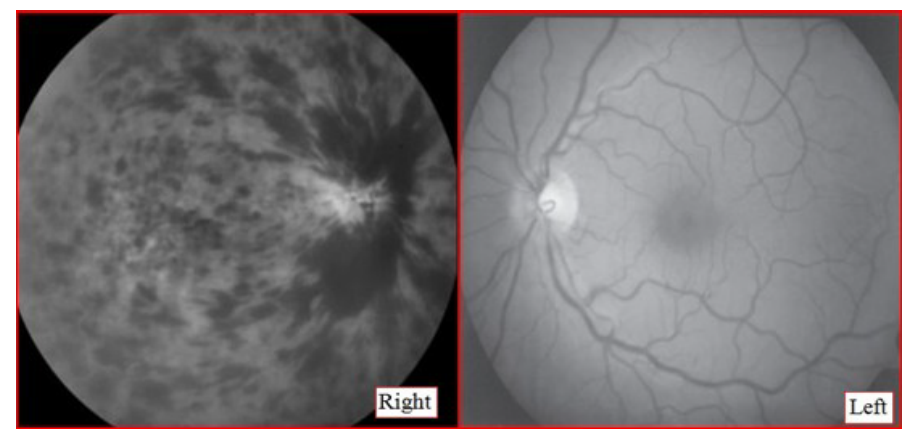

Figure 1. Fluorescein angiography confirmed the clinical picture of ischaemic central retinal vein occlusion in right eye and normal pattern in left eye

\begin{tabular}{|c|c|c|c|c|}
\hline Test & Value & \multicolumn{3}{|c|}{ Definition } \\
\hline $\mathrm{Hb}$ electrophoresis & 9 & \multicolumn{3}{|c|}{-} \\
\hline WBC & $13800 / \mathrm{mm}^{3}$ & \multicolumn{3}{|c|}{-} \\
\hline platlet & $700000 / 3$ & \multicolumn{3}{|c|}{-} \\
\hline \multicolumn{5}{|c|}{ FBS } \\
\hline \multirow{3}{*}{ D-Deimer } & \multirow{3}{*}{400} & \multicolumn{3}{|c|}{ Specimen: Plasma } \\
\hline & & \multicolumn{3}{|c|}{ In Conventional Units: $\leq 250$ ng/mL D-dimer units (DDU) } \\
\hline & & \multicolumn{3}{|c|}{ In SI Units: $\leq 0.50 \mathrm{mcg} / \mathrm{mL}$ fibrinogen equivalent units (FEU) } \\
\hline PT & 12 & \multicolumn{3}{|c|}{-} \\
\hline PTT & 32 & \multicolumn{3}{|c|}{-} \\
\hline fibrinogen & - & \multicolumn{3}{|c|}{300} \\
\hline LDH & 3996 & \multicolumn{3}{|c|}{-} \\
\hline Lupus Anticoagulant $\mathrm{Ab}(\mathrm{LAC})$ & 3.5 & \multicolumn{3}{|c|}{-} \\
\hline Anti Cardiolipin Ab(ACLA) & 2.5 & \multicolumn{3}{|c|}{-} \\
\hline BUN & 12 & \multicolumn{3}{|c|}{-} \\
\hline Creat & 0.4 & \multicolumn{3}{|c|}{-} \\
\hline \multirow{2}{*}{ FDP(fibrin deposit product) } & \multirow{2}{*}{35} & \multicolumn{3}{|c|}{ Normal Values } \\
\hline & & \multicolumn{3}{|c|}{ The result is normally less than 10 micrograms per milliliter $(\mathrm{mcg} / \mathrm{mL})$. } \\
\hline D.coombs & Negative & \multicolumn{3}{|c|}{-} \\
\hline Ind.coombs & Negative & & - & \\
\hline ANA & Normal & & - & \\
\hline Anti-SSA & Normal & & - & \\
\hline Anti-RNP & Normal & & - & \\
\hline$C_{3}$ & $0 \Omega$ & The $\mathrm{nc}$ & iges of $\mathrm{C} 3$ and $\mathrm{C} 4$ do not & h age. \\
\hline 23 & 0.4 & & C3 $0.65-1.65 \mathrm{~g} / \mathrm{L}$ & \\
\hline $\mathrm{C} 4$ & 0.32 & & C4 $0.16-0.60 \mathrm{~g} / \mathrm{L}$ & \\
\hline & & CH50 Values & $\%$ of Reference values & Interpretation \\
\hline $\mathrm{CH} 50$ & 350 & $<100$ & $0-50$ & Absent or low \\
\hline СH5O & 350 & $100-300$ & 51 to 150 & Normal \\
\hline & & $>300$ & $>150$ & High \\
\hline Anti-DNA & Normal & & - & \\
\hline CD55 & 70 & & Normal Values & \\
\hline CD59 & Negative & & - & \\
\hline p-ANCA & Normal & & - & \\
\hline Lipoprotein(a) & High & & - & \\
\hline ESR & 12 & & - & \\
\hline Homocysteine & Normal & & - & \\
\hline Factor V Liden & Negative & & - & \\
\hline Prothrombine G20210A mutation & Negative & & - & \\
\hline Factor VIII & $70 \%$ & & - & \\
\hline Prot C & $90 \%$ & & - & \\
\hline Prot S & $100 \%$ & & - & \\
\hline TG & 125 & & - & \\
\hline Chol & 200 & & - & \\
\hline Folate level & 10 & & Normal & \\
\hline B12 level & 500 & & Normal & \\
\hline Anti thrombine III & $100 \%$ & & Normal & \\
\hline
\end{tabular}

Table 1. Test report. 
error, but hyperhomocysteinemia is a correctable potential risk factor for central retinal vein occlusion and may suggest a poor prognosis in patients with CRVO. Because administration of folate and B12 does not have any side effects for patients we prescribed them for our patient for 3 years and he was treated with anticoagulant agents for occurrence of disease in young age in absence of acquired risk factors.

Although some experts believe that there are RVO patients without acquired risk factors, they were screened by extensive, expensive hereditary thrombophilia testing [8].

Therefore, thrombophilic screening is advised among simultaneous bilateral disease or existence of past personal or family history of thrombosis and in acquired risk factor for thrombophilia, especially in younger patients ( $<50$ years old).

\section{Conclusion}

The role of thrombophilic risk factors in RVO is still controversial, especially in CRVO [9]. A more comprehensive thrombophilia screening may be warranted in selected cases such as young patients or severe cases or bilateral RVO.

\section{Acknowledgement}

The authors would like to express our special thanks to Sheryl Nikpour for English editing of the manuscript.

\section{References}

1. Fegan CD. Central retinal vein occlusion and thrombophilia. Eye. 2002;16:98-106.
2. Soare AM, Popa C. Deficiencies of proteins C, S and antithrombin and factor $\mathrm{V}$ Leiden and the risk of ischemic strokes. J Med Life. 2010;3:235-238.

3. Cugati S, Wang JJ, Knudtson MD, et al. Retinal vein occlusion and vascular mortality: Pooled data analysis of 2 populationbased cohorts. Ophthalmology. 2007;114:520-4.

4. Cushman M. Epidemiology and risk factors for venous thrombosis. Semin Hematol. 2007;44:62-9.

5. Tait $\mathrm{C}$, Baglin $\mathrm{T}$, Watson $\mathrm{H}$, et al. Guidelines on the investigation and management of venous thrombosis at unusual sites. British J Hematology. 2012;159:28-38.

6. Bottós JM, Aggio FB, Dib E, et al. Impending central retinal vein occlusion associated with cilioretinal artery obstruction. Clin Ophthalmol. 2008;2:665-8.

7. Lahey JM, Tunç M, Kearney J, et al. Laboratory evaluation of hypercoagulable states in patients with central retinal vein occlusion who are less than 56 years of age. Ophthalmology. 2002;109:126-31.

8. Janssen MC, den Heijer M, Cruysberg JR, et al. Retinal vein occlusion: A form of venous thrombosis or a complication of atherosclerosis?. Thromb Haemost. 2005;94:1021-6.

9. Kolar P. Risk factors for central and branch retinal vein occlusion: A meta-analysis of published clinical data. J Ophthalmology. 2014;2014.

\section{*Correspondence to:}

Babak A

Department of Pediatrics

Lorestan University of Medical Sciences

Khoramabad Lorestan

Iran

Tel: +989183605274

E-mail: b.abdolkarimi@yahoo.com 